American Journal of Applied Sciences 9 (10): 1729-1735, 2012

ISSN 1546-9239

(C) 2012 Science Publication

\title{
Development of a Electrically Inspired Low Emission Microcontroller Based Hybrid Vehicle
}

\author{
${ }^{1}$ Habib Ullah, M., ${ }^{1}$ T.S. Gunawan, ${ }^{1}$ Sharif M. Raihan and ${ }^{2}$ Riza Muhida \\ ${ }^{1}$ Department of ECE, Faculty of Engineering, \\ International Islamic University Malaysia, Malaysia \\ ${ }^{2}$ Surya College of Education, \\ Summarecon Gading Serpong, Tangerang, Banten 15810, Indonesia
}

\begin{abstract}
Problem statement: Recently, influx of research afford is being concentrated in automobile engineering to develop low emission hybrid electric vehicle to reduce the greenhouse gases such as hydro-carbons, carbon monoxide, carbon dioxide, produces from the vehicle. Approach: Hybrid Electric Vehicles (HEVs) powered by electric machines and an Internal Combustion Engine (ICE) are a promising mean of reducing emissions and fuel consumption without compromising vehicle functionality and driving performances. Reduction of emission is a significant issue to save the environment from pollution that cause of many diseases in urban areas is almost entirely due to transport using fossil fuel. Although zero emission transport has not been developed and used practically yet. Results: This study introduce a control mechanism for alternative hybrid electric vehicle combination of electric motor and gasoline engine that reduce the use of fossil fuel without compromising the overall car performance. Conclusion: In this study, a microcontroller based control mechanism of HEV is introduced which consists of battery, voltage indicator, DC motor controller and battery charger.
\end{abstract}

Key words: Hybrid electric vehicle, low emission, microcontroller, battery, DC motor

\section{INTRODUCTION}

The automobile industry continues to grow by leaps and bounds and due to the increase in the number of vehicle worldwide, air-pollution continues to increase. Though the automobile manufacturers have reduced the greenhouse gases such as hydro-carbons, carbon monoxide, carbon dioxide from the vehicle, they cannot produce a zero-emission vehicle unless they produce an Electric Vehicle (EV) (Salisa et al., 2011). Technically, the quest for higher fuel economy is shaped by two major factors: how efficiently a power train converts fuel energy into useful power and how sleek a vehicle is in terms of mass, streamlining, tire resistance and auxiliary loads (the latter referring to power-consuming on-board services not related to the power train itself). On the other hand, vehicle functionality and comfort are shaped by various other factors, many of which run counter to higher fuel economy (Butler et al., 1999). Examples abound, from the way torque converter sacrifices efficiency to provide better shift smoothness and responsiveness to the wide variety of features that add mass to a vehicle. The beauty of the HEV is that energy can be fed back into the battery for storage, e.g., during regenerative braking (which is otherwise wasted as heat in a conventional vehicle). Leading car manufacturers like Toyota and Honda have already started mass producing HEV cars, Prius and Insight respectively, which are now becoming very popular among the consumers for their incredible mileage and less emissions. Aside from that, a number of automotive manufacturers are marketing hybrid vehicles for the general population, examples are DaimlerChrysler, Mitsubishi, Nissan, Fiat, Renault, Ford, GM and Subaru (Dorrell et al., 2012; Abdul-Hak and Al-Holou, 2009). Although the number for alternative electric vehicles is not significantly higher when efficiency is evaluated on the basis of conversion from crude oil to traction effort at the wheels, it makes a difference.

In recent days, several prototype and series production HEVs are known with electric motor power up to $80 \mathrm{~kW}$. That means, the whole range of hybridization is covered and there is not a clearly leading technology detectable (Maskey et al., 1999). With regard to vehicles with increased inertia weight like sports utility vehicles, medium and full HEVs seem to be preferred systems, where most of them are operated by an electric motor power between 30 and 70 $\mathrm{kW}$ and an ICE power between 90 and $130 \mathrm{~kW}$. 
Am. J. Applied Sci., 9 (10): 1729-1735, 2012

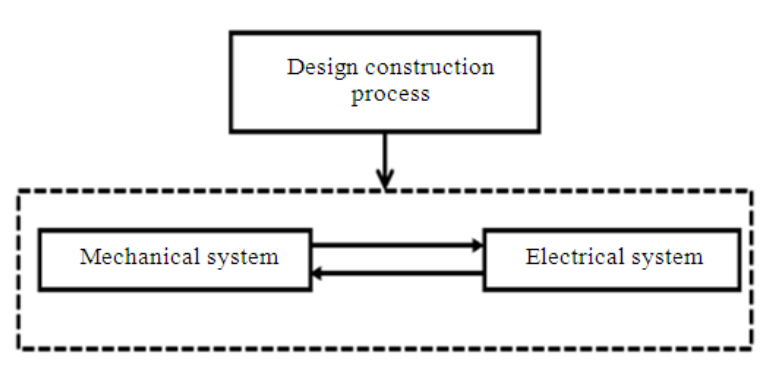

Fig. 1: The block diagram of HEV

Gasoline concepts are still dominating the HEV technology, supposing that the higher manufacturing costs and weight are the main arguments against the self ignition concept (James and John, 2004). A HEV model is designed based on certain specifications and requirements. The block diagram of the proposed HEV model is shown in Fig. 1.

\section{MATERIALS AND METHODS}

A model hybrid electric vehicle is designed based on certain specifications and requirements. Furthermore, the hybrid vehicle system is large and complex, involving multidisciplinary knowledge. The key to designing such a large system is to divide and conquer. The component-level design begins where propulsion unit, the energy source and other auxiliary units are specified. As design is an iterative process, that starts with some known factors and other educated estimates or assumptions allowed to be followed by scientific analysis in order to meet the requirements.

Mechanical design: Chassis is the most important part of the mechanical component of the vehicle. The angle aluminum is chosen as the main material for the construction of the chassis. There are several advantages to use angle aluminum for the construction of the chassis for the suggested HEV model, such as light weight, easy to handle and high strength. The hybrid electric configuration allows for a downsizing of the engine, since the electric motor can supplement the torque to achieve the desired acceleration (Jene et al., 2004). The selected engine is BG-328 brush cutter, with peak power $0.81 \mathrm{~kW}$. Important advantages of this engine include fuel efficiency and weight. A detailed specification of the gasoline engine is provided in Table 1.

Current internal combustion hybrid cars tend to use $\mathrm{AC}$ induction motors due to both the power requirements and the generally increased efficiency over commutated DC motors. However for smaller lowspeed vehicles the desire would be to use some form of DC motor to decrease the overall complexity of the vehicle (Husain, 2010). The use of a DC motor would reduce the power conditioning requirements by eliminating the need for an inverter from $\mathrm{DC}$ to $\mathrm{AC}$ power.
Table 1: Specifications of gasoline engine

\begin{tabular}{ll}
\hline Parameter & Value \\
\hline Model & BG- 328 \\
Engine type & 2 cycle, single cylinder, gasoline engine \\
Displacement & $30.5 \mathrm{cc}$ \\
Maximum output & $0.81 \mathrm{~kW}$ \\
Fuel & Mix fuel of gasoline and 2 cycle oil \\
Dimension $(\mathrm{LxWxH})$ & $345 \times 280 \times 401 \mathrm{~mm}$ \\
Dry weight & $9.4 \mathrm{~kg}$ \\
Supplier & OTONANI Co. Ltd \\
\hline
\end{tabular}

Table 2: Specifications of DC motor

\begin{tabular}{ll}
\hline Parameter & Value \\
\hline Horse Power Cont. & $40 \mathrm{~W}$ \\
Torque & $0.1 \mathrm{Nm}$ \\
Voltage and Current & $12 \mathrm{~V} \mathrm{DC}$ and 0.6A \\
RPM & 1800 \\
Reversibility & Reversible \\
Length of Motor (excluding spindle) & $99 \mathrm{~mm}$ \\
Diameter of Motor & $82 \mathrm{~mm}$ \\
Length of Spindle & $12.5 \mathrm{~mm}$ \\
Diameter of Spindle (with a flat) & $6.6 \mathrm{~mm}$ \\
Weight per motor & $1.9 \mathrm{LB}$ \\
\hline
\end{tabular}

Despite being slightly less efficient, the reduced expense and balance of plant obtained by using DC motors makes them more suitable for low speed hybrid vehicles. The specification of the DC motor used in this study is tabulated in Table 2. In the mechanical part SLA battery, alternator, wheels, transmission and belting has also taken in to account.

Electrical design: Design of the electrical part of is complicated and important for the HEV modeling. Microcontroller is used for control mechanism and PIC $16 \mathrm{~F} 877 \mathrm{~A}$ is used in this study. The overall electrical functionality is illustrated in Fig. 2. It has 40 pins and 5 Input-Output (I/O) ports. Port A consists of 6 pins which can be set up as either digital I/O or analog inputs. Port B is an 8-pin port which can be used for both digital I/O operations and In-Circuit Debugger (ICD) operations. Port $\mathrm{C}$, on the other hand, is a 5-pin multi-functional port, which can be used for digital I/O, as Capture-Compare (CCP) input, or Pulse-Width Modulation (PWM) output. Moreover, it can be used as Universal Asynchronous Receiver/Transmitter (UART) for serial communications.

Port $\mathrm{D}$ is an 8-pin port, which can be used for both digital I/O as well as Parallel Slave Port (PSP) functions. Finally, Port E is a 3-pin port, which is used for external memory connections. Its speed and program memory size are sufficient for applications of this study. The numbers of I/O pins are high enough to allow the use of many peripherals. In the current application many I/O pins including the analog inputs are not used; however, their presence allows the system to be expandable later by adding several other peripherals. 


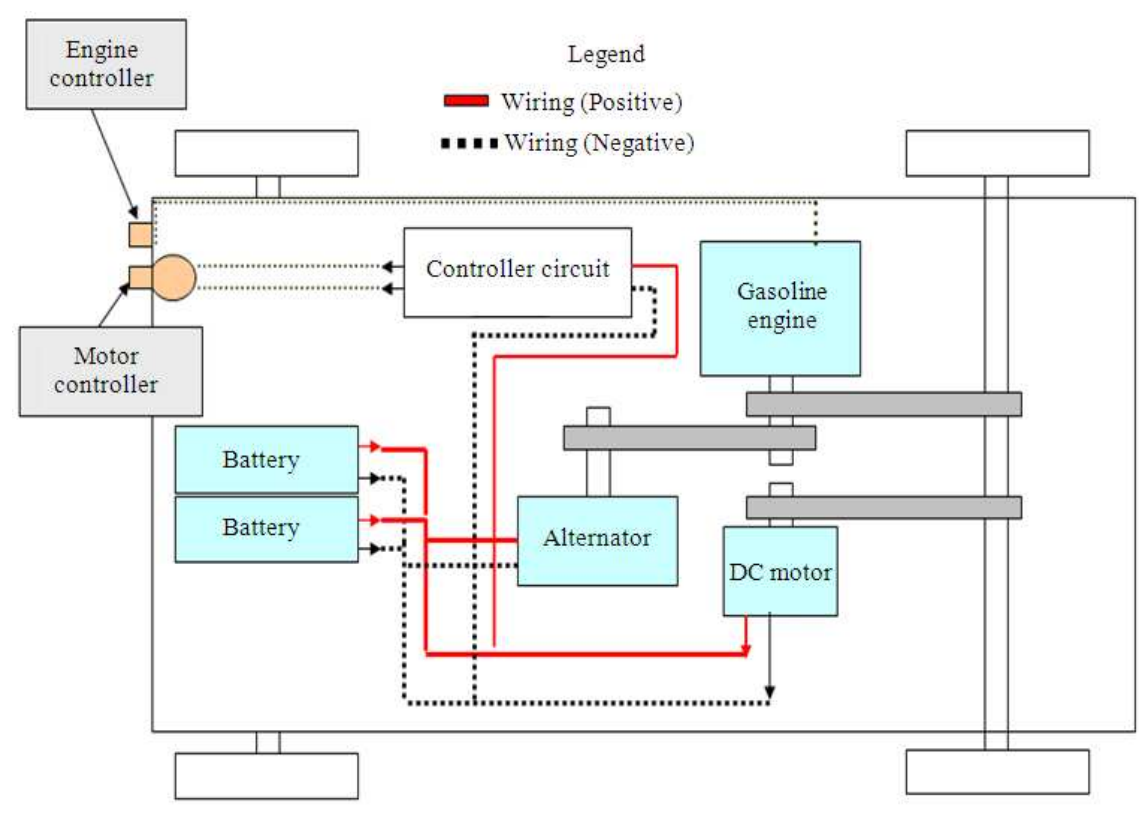

Fig. 2: The functionality diagram of the electrical part of the proposed HEV model

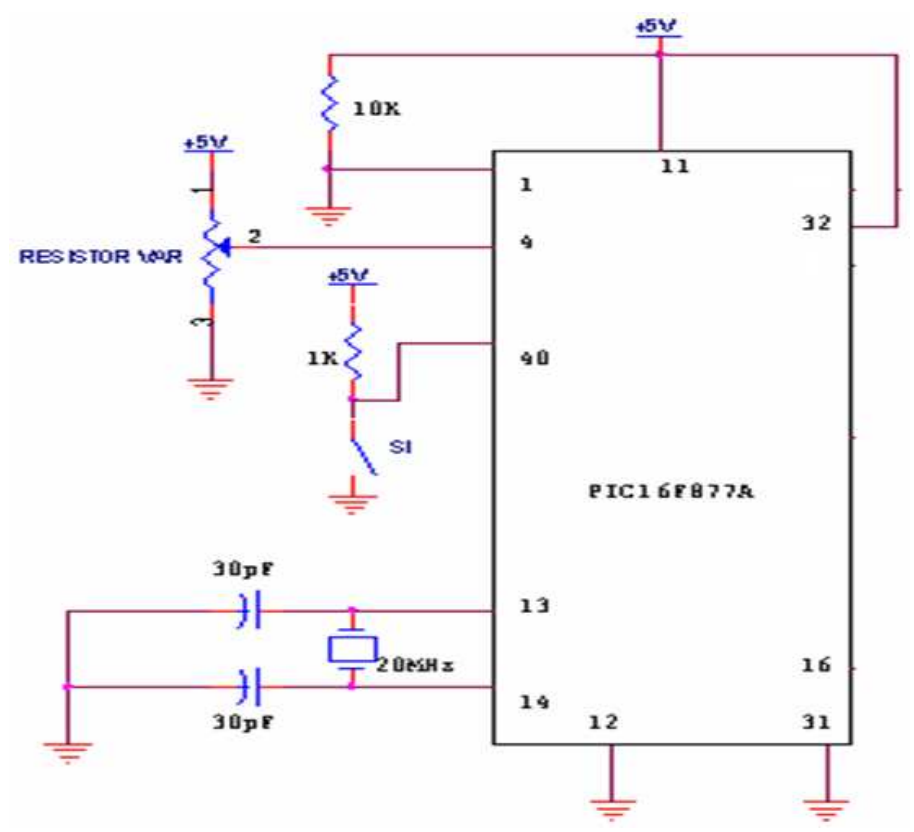

Fig. 3: The microcontroller clock and input connection

The availability of the two PWM outputs is an important feature since it is very easy to control DC motors by PWM. The microcontroller clock input circuit is illustrated in Fig. 3 and the PWM output signal with 50 and $70 \%$ duty cycle is shown in Fig. 4.

The battery voltage analyzer circuit is built around the popular quad op-amp LM324 that has 4 separate op- amps (A through D) with differential inputs. Op-amp have been used here as comparators. Switch S2 is a push switch, which is pressed momentarily to check battery voltage level before charging the battery, if it is needed. The non-inverting terminals of op-amp A through $\mathrm{D}$ are connected to the positive supply rail via a potential divider chain comprising resistors R1 through R5. 
Am. J. Applied Sci., 9 (10): 1729-1735, 2012

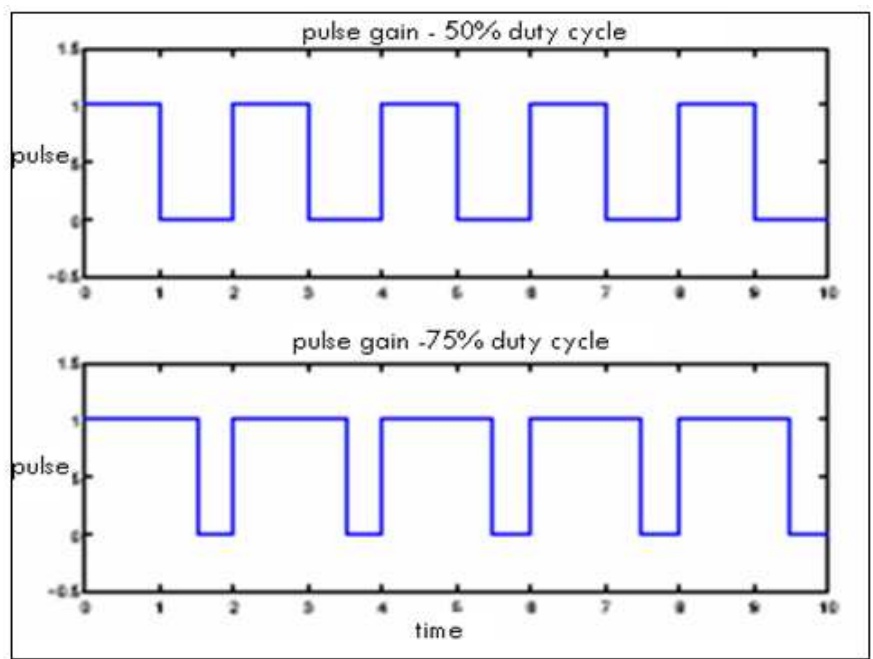

Fig. 4: PWM signals with 50 and $75 \%$ duty cycles

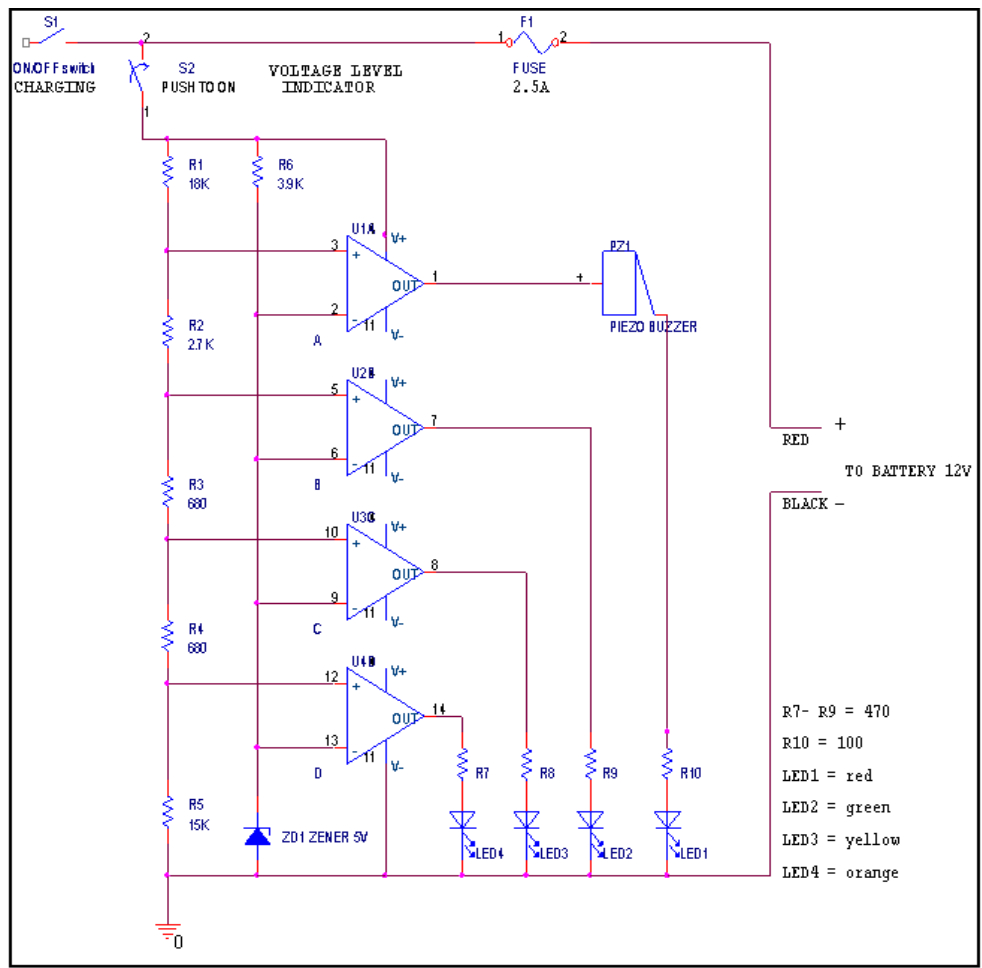

Fig. 5: Battery voltage indicator schematic diagram

Table 3: Status of LEDs of the battery voltage indicator circuit

\begin{tabular}{llllll}
\hline & Status of LEDs & & & & \\
Battery voltage & Red & Green & Yellow & Orange & Comments \\
\hline$<9.8 \mathrm{~V}$ & Off & Off & Off & Off & Buzzer off \\
$>9.8 \mathrm{~V}$ & On & Off & Off & Off & Danger level \\
$11.5 \mathrm{~V}$ & On & On & Off & Off & Low level \\
$12.0 \mathrm{~V}$ & On & On & On & Off & Normal level \\
$12.5 \mathrm{~V}$ & On & On & On & On & High level \\
\hline
\end{tabular}


Thus the voltage applied to any non-inverting input is the ratio of the resistance between that non-inverting terminal and ground to the total resistance $(\mathrm{R} 1+\mathrm{R} 2+\mathrm{R} 3+\mathrm{R} 4+\mathrm{R} 5)$. The resistor chain provides a positive voltage of above $5 \mathrm{~V}$ to the non-inverting inputs of all op-amps when battery voltage is $12.5 \mathrm{~V}$ or more. A reference voltage of $5 \mathrm{~V}$ is applied to the inverting inputs of op-amps via $5 \mathrm{~V}$ zener diode $\mathrm{ZD} 1$. When the circuit is connected to the battery and push switch S2 is pressed, the battery voltage is sampled by the analyzer circuit. If the supply voltage sample applied to the non-inverting input of an op-amp exceeds the reference voltage applied to the inverting inputs, the output of the op-amp goes high and the LED connected at its output lights up. The different levels of battery voltages are indicated by LED1 through LED4. All the LEDs remain lit when the battery is fully charged (above 12.5V). The circuit of the battery voltage indicator is shown in Fig. 5. The buzzer connected to the output of IC1 also sounds (when S2 is pressed) as long as the voltage of battery is above $9.8 \mathrm{~V}$. If the voltage level goes below $9.8 \mathrm{~V}$, the buzzer goes off; this indicates that it is time to replace the battery or recharge. The status of LEDs for different battery voltages is shown in the Table 3 . By changing the duty cycle of a pulse sequence one can change the average power supplied by that sequence. Therefore, the speed of the motor will change based on the duty cycle (i.e., average power) of the pulse sequence. For example, if the motor has $75 \mathrm{rpm}$ (reverse per minute) with a $75 \%$ duty cycle, it will have approximately $50 \mathrm{rpm}$ with $50 \%$ duty cycle signal. As per manufacturer's data sheets, a $12 \mathrm{~V}$ rechargeable lead-acid battery should be operated within $10.1 \mathrm{~V}$ and $13.8 \mathrm{~V}$. When the battery charges higher than $13.8 \mathrm{~V}$ it is said to be overcharged and when it discharge below $10.1 \mathrm{~V}$ it can be deeply discharged.

A single event of overcharge or deep discharge can bring down the charge-holding capacity of a battery by $15-20 \%$. In this study, the charging is controlled by the microcontroller. The program will stop from charging when the voltage of the battery is $11.8 \mathrm{~V}$. Below than the value of $11.8 \mathrm{~V}$, it will stop the motor operationmode and start charging the battery.

\section{RESULTS AND DISCUSSION}

Throughout the motored vehicle evolution, there have always been concept and prototype cars combining the advantages of two different propulsion systems, which include a second power source and energy storage device to supplement the fuel tank. No universal control strategy is in use. The design of HEVs permits great flexibility, allowing the designers to optimize for a number of different benefits, such as fuel economy, emissions, cost of the vehicle and safety. The work flow diagram in Fig. 6 shows the basic principle of the HEV system of this study. At start, the engine must be put to $\mathrm{ON}$ mode and the voltage indicator switch turned on to check the battery voltage before the operation can be run by the DC motor.

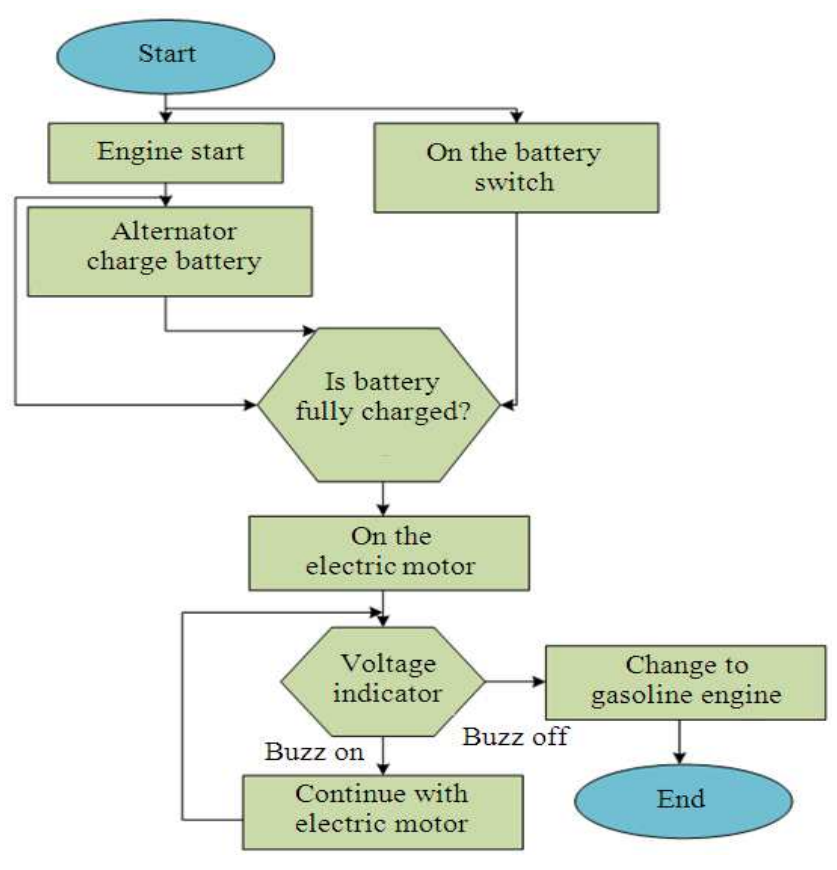

Fig. 6: The work flow diagram of the proposed HEV model. 
Am. J. Applied Sci., 9 (10): 1729-1735, 2012

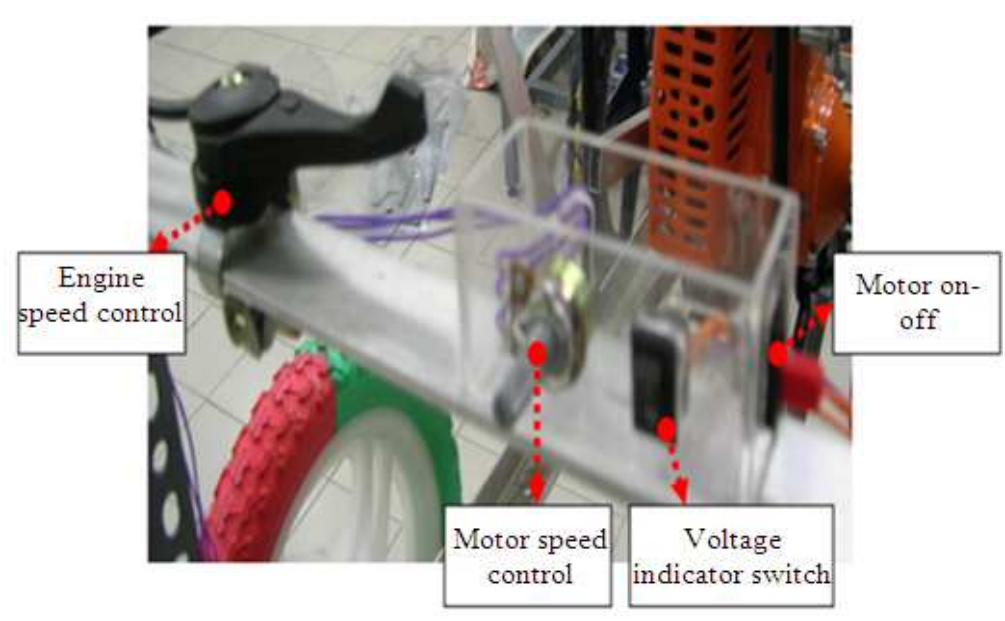

Fig. 7: The proposed HEV model

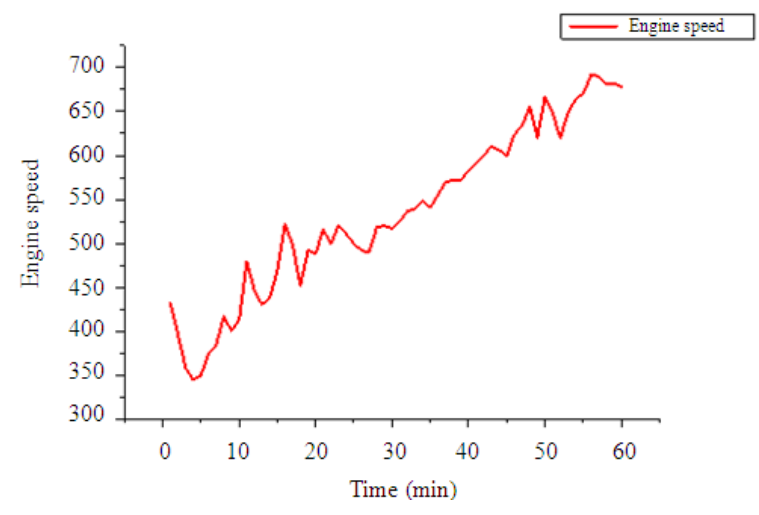

Fig. 8: Engine speed performance with time

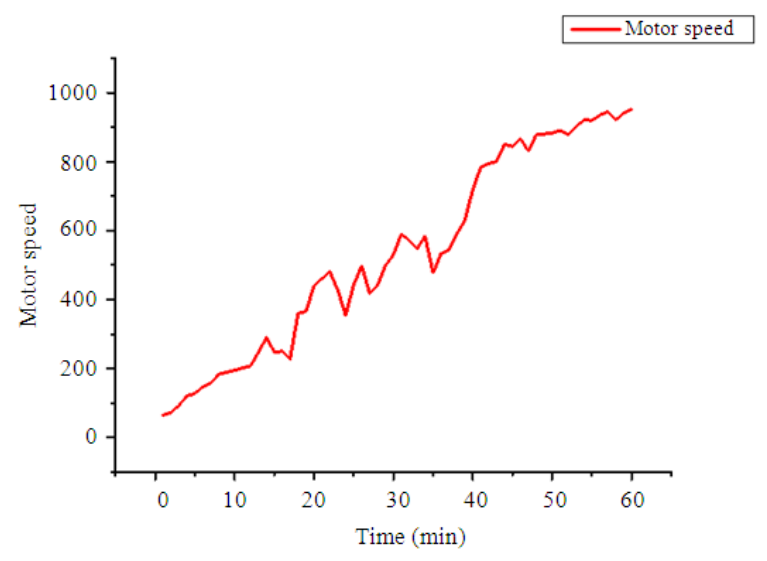

Fig. 9: Motor speed performance with time

It means that, if the buzzer of the voltage indicator did not produce any sound and no LED lights up, the batteries have insufficient voltage to power the motor and thus cannot run in motor-mode and must be recharge before can be used.

In other condition, provided there is enough voltage to move the electric motor, the mode is changed to motor-mode instead of engine-mode. This is detected by the software program that controls the on-off of the battery charging process by analyzing the analog input from the battery. The program will start to recharge the battery at voltage value $=11.8 \mathrm{~V}$. The program is also set to be able to move forward and reverse by a button switch as a mean to do so. The implemented model of the proposed HEV is illustrated in Fig. 7. Fig. 8 shows the engine speed performance with time. While the motor speed that can start at low torque shows it can achieve higher speed over time. The performance of the motor speed with time is shown in Fig. 9.

The graph generated using Origin Pro software based on the data collected during the performance test of the model. The duration of each test is 1 hour. The result is in agreement with the discussion. It shows that the gasoline engine that requires higher starting torque tend to have low and constant speed when combined.

\section{CONCLUSION}

An electrically inspired low emission hybrid car model is presented in this article. It is observed from the model that, not only does it balance an electric motor and a gasoline engine, but it manages to use a minimum amount of fuel and release a minimum amount of emissions. The proposed HEV model can turn the engine and the motor on and off, as long as one of them is powering the car. When the engine is on, it runs, as much as possible, in its island of minimum fuel consumption, getting as much energy as possible out of the gasoline. If not all of the energy is needed to drive 
the car, some of it can be stored in the battery and saved for later. The only recharging necessary is refueling by going to the gas station. Also, there is not the same demand on the batteries as there would be in an electric vehicle, where the batteries must store all the energy the car needs.

\section{REFERENCES}

Abdul-Hak, M. and N. Al-Holou, 2009. ITS based predictive intelligent battery management system for plug-in hybrid and electric vehicles. Proceedings of the IEEE Vehicle Power and Propulsion Conference, Sept. 7-10, IEEE Xplore Press, Dearborn, MI., pp: 138-144. DOI: 10.1109/VPPC.2009.5289858

Butler, K.L., M. Ehsani and P. Kamath, 1999. A MATLAB-based modeling and simulation package for electric and hybrid electric vehicle design. IEEE Trans. Vehic. Technol., 48: 1770-1778. DOI: 10.1109/25.806769

Dorrell, D.G., A.M. Knight, L. Evans and M. Popescu, 2012. Analysis and design techniques applied to hybrid vehicle drive machines-assessment of alternative ipm and induction motor topologies. IEEE Trans. Industrial Elect., 59: 3690-3699. DOI: 10.1109/TIE.2011.2165460
Husain, I., 2010. Electric and Hybrid Vehicles: Design Fundamentals. 2nd Edn., CRC Press, ISBN-10: 143981175X, pp: 501.

James, L. and J. Lowry, 2004. Electric Vehicle Technology Explained. 1st Edn., John Wiley and Sons, Chichester, ISBN-10: 0470090693, pp: 314.

Jene, H., E. Scheid and H. Kemper, 2004. Hybrid Electric Vehicle (HEV) concepts-fuel savings and costs.

Maskey, M., M. Parten, D. Vines and T. Maxwell, 1999. An intelligent battery management system for electric and hybrid electric vehicles. Proceedings of the IEEE 49th Vehicular Technology Conference, May 16-20, IEEE Xplore Press, Houston, TX, pp: 1389-1391. DOI: 10.1109/VETEC.1999.780575

Salisa, A.R., N. Zhang and J.G. Zhu, 2011. A comparative analysis of fuel economy and emissions between a conventional HEV and the UTS PHEV. IEEE Trans. Vehic. Technol., 60: 4454. DOI: $10.1109 /$ TVT.2010.2091156 